\title{
The Canadian Andropause Society at work
}

\author{
Roland R Tremblay DSc MD PhD \\ President, Canadian Andropause Society
}

$\mathrm{T}$ The main goal of the Canadian Andropause Society (CAS) since its foundation in early 1998 has been to provide information and continuing education about andropause to physicians and pharmacists. These education and awareness programs target the diagnosis, treatment and monitoring of aging men experiencing the clinical manifestations of androgen deficiency. After one year (1997 to 1998) of intensive work, the Quebec Task Force on Andropause and the CAS were able to present to Canadian physicians lectures and workshops, which covered general issues related to andropause.

Because the subject of andropause is controversial by nature, as the subject of menopause was 30 years ago, the CAS decided that 2001 was an ideal year to revisit knowledge about andropause by having renowned investigators address new issues such as those discussed in this second issue of the Journal of Sexual \& Reproductive Medicine. These issues will be a part of the scientific program of the Second Congress of the CAS to be held in January 2002. Grouping so many articles in one issue should facilitate the work and role of physicians who will be delivering new lectures across the country over the coming two years, developing teaching methods adapted to various health professionals and promoting Canadian interests in several other countries where andropause is also seriously considered to be a comorbidity factor that is associated with the irremediable aging process.

To all of my colleagues who have dedicated hours and days of their precious time - time that has sometimes been borrowed from their family lives, their holidays or their tranquility after 21:00 - I offer my most sincere thanks, along with those of the executive members of the CAS, for their outstanding contribution to the new training program.

I also appreciate the constant support that was provided by Dr Richard W Casey, editor-in-chief of the Journal of Sexual E Reproductive Medicine, and the assistance of Pulsus Group Inc.

The development of the new training program was made possible because of unrestricted grants to continuing medical education received from Organon Canada, Solvay Canada, Paladin Laboratories, Canada and Pfizer Canada. These private organizations should also benefit from the vast amount of knowledge presented in this issue. 